\title{
BRYOPHYTE EXTRACTS WITH ACTIVITY AGAINST PLANT PATHOGENIC FUNGI
}

\author{
Mekuria Tadesse ${ }^{1,}$, U. Steiner ${ }^{1}$, H. Hindorf ${ }^{1}$ and H-W. Dehne ${ }^{1}$ \\ ${ }^{1}$ Institute for Plant Diseases, Nussallee 9, D-53115 Bonn, Germany, E-mail : Mekuria_t@hotmail.com \\ ${ }_{2}^{2}$ Ethiopian Agricultural Research Organisation, P O Box 2003, Addis Ababa, Ethiopia
}

\begin{abstract}
The effects of extracts from 17 different bryophyte species were investigated against economically important plant pathogenic fungi. In vitro experiments showed that ethanol extracts of bryophytes inhibited mycelial growth of Botrytis cinerea and Alternaria solani. Extracts from Bazzania trilobata, Diplophyllum albicans, Sphagnum quinquefarium, Dicranodontium denudatum, and Hylocomium splendens inhibited fungal development by over $50 \%$. Green pepper plants sprayed with the extracts from 17 bryophytes (at $1 \% \mathrm{mv}^{-1}$ ), with the fungicide dichlofluanide (50 ppm), and untreated plants were compared. Treatments were applied 4 hours prior to inoculation with conidial suspension of the grey mould $(B$. cinerea). Significant variations between treatments were detected. Extract treatments reduced the grey mould severity ranging from 15 to $23 \%$, whereas dichlofluanide showed efficacy up to $92 \%$. Three dose levels of five candidate extracts sprayed at three pre-infectional time intervals were compared under low and high inoculum pressures of the late blight, Phytophthora infestans, of tomatoes and powdery mildew, Blumeria graminis, of wheat. In general, extracts from B. trilobata and D. albicans showed better efficient disease protection than that of $S$. quinquefarium, D. denudatum, and $H$. splendens. The direct mode-of-action of treatments on the surface of leaves gave inefficient disease protection, evidenced on treated plants at 4 hours before the inoculation. However, plants treated by the same extracts at least 2 days before inoculation exhibited less than $90 \%$

disease severity. Therefore, products of bryophytes deserved to be reliable sources as biocontrol agents and may play significant roles for future practical applications in a socially and ecologically healthy crop management system.
\end{abstract}

\section{Key words/phrases: Alternaria solani, Blumeria graminis, Botrytis cinerea, Bryophyte extracts, Phytophthora infestans}

\section{INTRODUCTION}

Plant medicines are well recognised to serve as remedies of diseases in various forms. Similarly, before the discovery of the synthetic pesticides, plant-derived pesticides were a common theme (Jacobson and Crosby, 1971), and most evolved from local medicinal plants. Even today, botanicals as domestic agro-chemicals remain as an age-old practice of farmers in the tropics, sub-tropic and temperate regions. The current reports of Girma Tesfahun et al. (2000) provide evidences to this fact, which show the use of botanical pesticides by farmers in Welo region such as Phytolacca dodecandra, Euphorbia tirucalli, Croton marcrostachys and Aloe spp. to protect storage pests.

Without crop protection, $20-30 \%$ of the total crop production would virtually be lost in the world, with peak losses of up to $50 \%$ in developing countries. Without fungicides, fungal pathogens are estimated to cause $20 \%$ yield reduction in major food and cash crops (Oerke et al., 1994). Leaf fungal pathogens such as the early (Alternaria solani) and late blight (Phytophthora infestans) on potatoes and tomatoes, the grey mould (Botrytis cinerea) on vegetables and grapes, and the powdery mildew (Blumeria graminis) on cereals have worldwide economic impacts. In Ethiopia, for example, the late blight of potatoes caused crop loses on unimproved local cultivars and susceptible variety (Al-626) up to $100 \%$ and $67.1 \%$, respectively (Bekele Kassa and Yaynu Hiskias, 1996).

Options to control leaf fungal pathogens are different, but the use of fungicides still remains one of the principal pest management components. However, recent research policies in developing countries have shown that in many of the world's cropping systems price factors and non-price factors have created imbalance towards the use of chemical pest control methods (Ange, 1996). Problems of obsolete pesticide depositions and posing of toxicity dangers to the society in Western Ethiopia have resulted in government concerns that required for international aid for proper recycling (FAO, 2001). Nevertheless, natural products are generally considered to be biodegradable and safer than synthetic pesticides, because of their relatively short environmental half-lives and less suspected toxicology (Dayan et al., 1999). They serve as crude extracts, alternative sources of known fungicides, new leads for fungicides, and resistance inducers.

Bryophytes, commonly known as mosses, are non-woody vascular plants and taxonomically placed between algae and pteridophyta. About 20000 species of mosses are described world wide 
and divided into the classes Anthocerotae (hornworts), Hepaticae (liverworts) and Musci (mosses). In Ethiopia, there exist about 290 taxa of mosses (O'Shea, 1997). In the Bale Mountains National Parks, a great diversity of bryophytes was found counting 51 and 118 taxa of Hepaticae and Musci, respectively (Miehe and Miehe, 1994). Mosses are commonly recognised by a densely grown mat of small plants on cereal hayricks covering roofs of many traditional houses.

So far, a myriad of phytochemical constituents and medicinal uses of products from bryophytes, especially various secondary metabolites such as derivatives of benzoic acids and cinnamic acids, phenols, terpenoids and flavonoids have been reported (Asakawa and Heidelberger, 1982; Ando and Matsuo, 1984). Bryophytes have been used in the traditional folk medicine in China (Ding, 1980) and North America (Ando and Matsuo, 1984). But there exists until yet little or no practical knowledge how to use such resources to the benefit of crop protection elsewhere in the world.

Therefore, the focus of this work was to characterise the antifungal activity of extracts from different bryophytes and to select species as sources of active components with high level of in vitro and in vivo activities against economically important leaf pathogenic fungi.

\section{MATERIALS AND METHODS}

\section{Sample collection and identification}

In 1997, samples of 17 bryophyte species, 4 species of Hepaticae [Scapania undulata (L.) Dum., Bazzania trilobata (L.) S.F. Gray, Pellia epiphylla (L.) Corda and Diplophyllum albicans (L.) Dum.] and 13 species of Musci [Hylocomium splendens (Hedw.) B.S.G., Bryum pseudotriquetrum (Hedw.) Schwaeger, Philonotis fontana (Hedw.) Brid., Sanionia uncinata (Hedw.) Loeske, Mnium hornum Hedw., M. undulatum Hedw., M. affine Funk, Plagiothecium undulatum (Hedw.) B.s.G., Dicranodontium denudatum (Brid.) Britt., Sphagnum quinquefarium (Braithw.) Warnst., Rhytidiadelphus loreus (Hedw.) Warnst., Polytrichum commune Hedw. and Dicranum scoparium Hedw.] were collected in the Vosges Mountains, France, surroundings of Cascade due Gehard near Le Val d' Ajol on granite and sandstone rocks at $400 \mathrm{~m}$ a.s.l. The taxonomic identification of individual species was covered by Frahm according to Frahm and Frey (1992). Samples were kept in drying chamber for 3 to 5 days at $60^{\circ} \mathrm{C}$ and cleaned from undesired materials and natural mixture of species.

\section{Preparation of moss extracts}

Ten $\mathrm{g}$ dry-weight of each sample, both the rhizoid and green herbal parts, was finely pulverised with a coffee grinder. Pulverised samples were add-mixed with $250 \mathrm{ml}$ ethanol $(70 \%)$ in $500 \mathrm{ml}$ Erlenmeyerflasks and extracted under reflux condition in a magnetic stir and warm-water-bath at $60^{\circ} \mathrm{C}$ for duration of 2 hours. The supernatants and pellets were separated by hydraulic vacuum filtration after adopting methods of Kurt (1997). The filtrates were stored at $4^{\circ} \mathrm{C}$ until further experimental needs.

Quantification of a concentration of each plant extract was determined as the percentage of the ratio of dry weights $(\mathrm{m})$ of each sample in relation to the amount of extraction solvents (v) (Friedland, 1997). By adopting and modifying this method, an amount of required volume $\left(\mathrm{V}_{\mathrm{n}}\right)$ of a sample extract for assay $(\mathrm{ml})$ was determined as,

$$
V_{n}=\left(C \times V_{N}\right) / D_{f}
$$

where: $\mathrm{C}=$ preferred concentration of an extract for bioassays (\%); $\mathrm{V}_{\mathrm{N}}=$ a stock volume of a sample extract $(250 \mathrm{ml})$; and $\mathrm{D}_{\mathrm{f}}=$ a constant for dilution factor that we employed $D_{\mathrm{f}}=10$.

\section{Plant pathogenic fungi}

Isolates of Botrytis cinerea Pers. ex. Fr., Alternaria solani (Ellis et Martin) Sorauer, Phytophthora infestans (Mont.) de Bary and Blumeria graminis DC. f. sp. tritici (Em.) Marchal were used in in vitro or in vivo bioassays. Culturing and maintenance of the former two fungi were performed on PotatoDextrose-Agar (PDA) (39 g medium in $1000 \mathrm{ml}$ aqua dest.) at $20 \pm 5^{\circ} \mathrm{C}$. P. infestans was cultured on vegetable juice-calcium carbonate agar $(200 \mathrm{ml} \mathrm{V}$ juice; $3 \mathrm{~g} \mathrm{CaCO}_{3} ; 16 \mathrm{~g}$ agar; $800 \mathrm{ml}$ aqua dest.) and maintained at $18^{\circ} \mathrm{C}$ in the dark. The pathogen $B$. graminis was maintained on susceptible wheat plants 'Kanzler' under glasshouse conditions.

\section{Cultivation of plants}

Green pepper, Capsicum annuum L. cv. 'Yolo Wonder B'; tomato, Lycopersicon esculentum (L.) Farw. cv. 'Rheinlands Ruhm'; wheat, Triticum aestivum L. cv. 'Kanzler' and 'Toronto' were the selected host plants to serve as assay indicator for antifungal activity of moss extracts. The plants were grown in commercial potting soil in plastic pots $(\phi 10 \mathrm{~cm})$. Seeds of tomato and green pepper were sown in pots and kept on benches in a glasshouse equipped with an automatic water supply to enhance seed emergence. One week after sowing, seedlings were thinned and transplanted for growing as single plants per pot. Seedlings of wheat were obtained by sowing 10 to 15 seeds per pot. All plants were cultivated at the following growth conditions in the glasshouse: 16 hours light period (approx. $7000 \mathrm{~lx}$ ), 60 to $80 \%$ relative humidity, $20 \pm 2{ }^{\circ} \mathrm{C}$, irrigation twice per day and $2 \%$ weekly supply of a nutrient solution. 


\section{Mycelium growth inhibition assay}

The effects of ethanolic extracts from 17 moss species on mycelial growth of $B$. cinerea and $A$. solani were tested. Each moss extract at concentrations of 0.05 and $0.1 \% \mathrm{~m} \mathrm{v}^{-1}$, and selected extract additionally at $0.5 \% \mathrm{~m} \mathrm{v}^{-1}$, was applied to the growing media (PDA) in petri-dishes, on which agar discs with one-week-old mycelium of the fungi were placed and incubated at room temperature. As controls served untreated or with $70 \%$ ethanol treated agar plates. All treatments were replicated five times in completely randomised design and the experiments with each fungus were conducted two times. Mycelial growth inhibition activity of each test substances was measured as radial growth $(\mathrm{cm})$ of the test fungi starting 2 days up to 15 days after culture inoculation. Visual observations for any change in culture characteristics of the test fungi were also considered.

\section{Screening for plant protection activity}

Preliminary screening of bryophyte extracts was carried out in B. cinerea/green pepper pathosytems. Three weeks old green pepper plants protectively sprayed with the ethanolic extracts from 17 moss species, each at $1 \% \mathrm{mv}^{-1}$ (in distilled water containing $0.0125 \%$ Tween 20 as surfactant), with the fungicide dichlofluanide (50 ppm), and untreated plants were compared. Treatments were applied 4 hours before inoculation with the pathogen. Every treatment was replicated four times in a completely randomised design. Inoculation with $B$. cinerea took place by spraying a conidial suspension counting $1 \times 10^{6}$ conidia $\mathrm{ml}^{-1}$. Inoculated plants were incubated in a moisture chamber at $20 \pm 5^{\circ} \mathrm{C}$ and $95 \%$ relative humidity for 48 hours. Disease severity was visually estimated as percentage of infected leaf area in relation to total healthy tissues of sampled leaves. Totally, 4 leaves per plant counting from bottom to top and 16 leaves per treatment were assessed. The mean grey mould severity data per replication was calculated to each treatment for further statistical analysis and efficacy computation.

\section{Determination of mode-of-action}

$P$. infestans on tomato and B. graminis on wheat were the selected pathosystems to determine the mode-of-action of the bryophyte extracts. Five candidate extracts (B. trilobata, D. albicans, S. quinquefarium, $H$. splendens and $D$. denudatum), each at three dose levels $\left(0.1,0.5,1.0 \% \mathrm{~m} \mathrm{v}^{-1}\right)$, and at three pre-infectional spray time intervals (4 hours, 2 and 5 days) were studied. The experiments were conducted first by using low inoculum density of each pathosystem, then repeated by using high inoculum density of the indicated pathosystem.
Untreated plants were accommodated to compare efficacy of test preparations. Each treatment was replicated four times in a Block Balanced Design (BBD). A four-weeks old tomato plant bearing four fully matured leaves was considered as single replication, whereas 10 to 15 wheat seedlings at two unfold leaf stages per pot were taken as a replication.

The low and high inoculum densities of $P$. infestans were achieved by $3 \times 10^{4}$ and $8 \times 10^{4}$ zoospores $\mathrm{ml}^{-1}$, respectively. Well-developed and sporulating cultures of $P$. infestans were utilised as inoculum sources, the biomass harvested as suspension in distilled water and subjected for separation of the mycelium and sporangia by filtration through a double-layered muslin-cloth on a glass funnel. Suspension of sporangia was kept at $4^{\circ} \mathrm{C}$ for 4 hours to induce the release of zoospores. The density of zoospores was microscopically adjusted according to the specific need of an experiment. A total of 12 pots (12 severely infected plants/pot) for low inoculum density and 24 pots (10 severely infected plants/pot) for high inoculum density were employed to create infection gradients of powdery mildew of wheat.

The $P$. infestans/tomato pathosystem was incubated in a moisture chamber at $20 \pm 5^{\circ} \mathrm{C}$ and $95 \%$ relative humidity for 64 hours and that of the $B$. graminis/wheat pathosystem for 9 to 10 days in a glasshouse. Disease severity of the late blight and mildew severity was visually quantified by rating a percentage of infected leaf area in relation to total healthy tissues of sampled leaves. Totally, four leaves of tomatoes (each bearing 12 leaflets per replication and 48 leaflets per treatment) were sampled for gathering of data. The severity of powdery mildew of wheat was rated on 5 primary leaves per replication and 20 leaves per treatment. The mean disease severity per replication was calculated to carry out statistical analysis and efficacy determination.

\section{Efficacy computation and statistical analysis}

Mycelial growth inhibition activity of each test substance was measured in vitro based on radial growth $(\mathrm{cm})$ of the test fungi. In vivo antifungal activities of bryophyte extracts were measured based on disease severity ratings. Mean values were subjected to computation of inhibition or efficacy responses by adopting the method of Abbott (1925).

$$
\text { Inhibition }(\%)=100\left[\left(U_{t}-T_{r}\right) / U_{t}\right]
$$

where: $U_{t}=$ mean value for untreated control and $\mathrm{T}_{\mathrm{r}}=$ mean value for treated with moss extracts.

The percentage of all disease data (in vivo) were subjected to logarithmic transformation to affirm the basic assumptions during the statistical variance analysis. Thereafter, the analysis of 
variance and multiple separation of means ( $\mathrm{t}$-test and Tukey-test, $\alpha<0.05, \mathrm{p}<0.05)$ were determined by using Sigma Stat, Jandel Scientific Inc. (SPSS, Version 2, 1997, USA).

\section{RESULTS}

\section{Inhibition of mycelial growth of Botrytis cinerea and Alternaria solani}

The screening of the ethanol extracts from 17 different bryophytes against mycelial growth of the tested fungal organisms showed significant differences between moss extracts. Highly significant differences between the moss extracts and untreated checks occurred. At 0.05 and $0.1 \% \mathrm{~m}$ $\mathrm{v}^{-1}$ the inhibition of radial mycelium growth for $B$. cinerea and A. solani ranged from $0-25 \%, 25-50 \%$, and more than $50 \%$. More than half of the tested substances showed low efficacy in the range of 0 $25 \%$ inhibition of mycelial growth of $B$. cinerea and A. solani. Among these were extracts from $B$. pseudotriquetrum, M. affine, S. uncinata and $S$. undulata against $B$. cinerea. Similarly, weak performances were observed from extracts of $S$. undulata, M. undulata, and P. epiphylla against $A$. solani (Fig. 1).

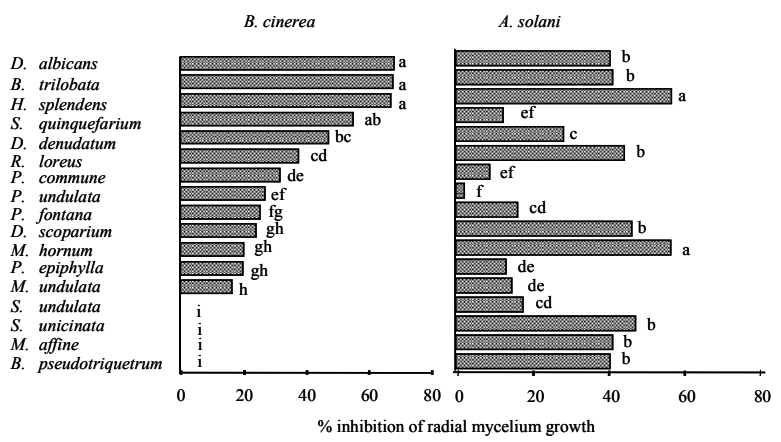

Fig. 1. Mycelium growth inhibitory activity of ethanolic extracts from different bryophytes at $0.1 \% \mathrm{mv}^{-1}$ against Botrytis cinerea and Alternaria solani. Mean values denoted by identical lower case letter (s) are not significantly different from each others for each tested fungi.( $\alpha$ $=0.05 ; \mathrm{p}<=0.001)$.

Extracts from R. loreus, P. epiphylla, P. commune, and M.undulatum exhibited moderate ranges of 25$50 \%$ antifungal activities against $B$. cinerea. However, a higher level of mycelial growth inhibitory activity of moss extracts $(>50 \%)$ was observed by applying extracts from $B$. trilobata, $D$. albicans, $H$. splendens, $D$. denudatum and $S$. quinquefarium against $B$. cinerea. Extracts from the former three species were also among the products inhibiting the growth of A. solani. A strong positive correlation between the concentration of substances and their antifungal activities was detected. This is illustrated in Figure 2, showing dose-dependent inhibitory activities of the extract from the leafy liverwort $B$. trilobata. The mycelial growth inhibitory effects of those substances were distinctly accompanied by some morphological changes of the tested fungi such as deformation of mycelial growth and reduction in conidia production and sclerotia formation of $B$. cinerea (Fig. 3).

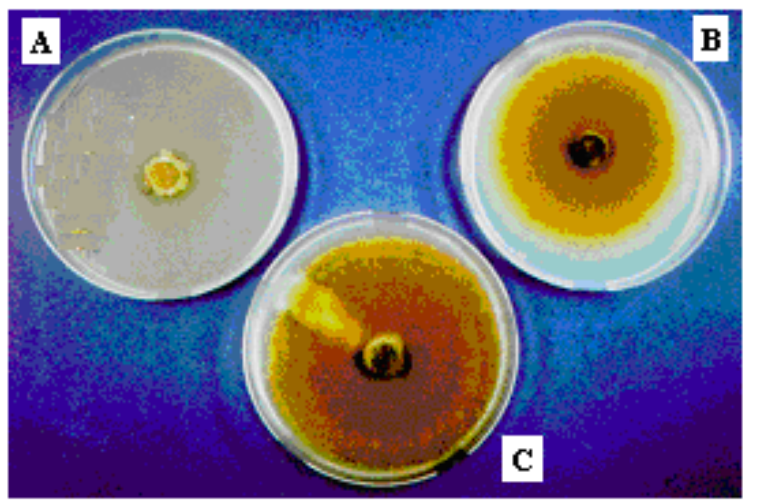

Fig. 2: Mycelium growth of Alternaria solani on PDA amended with extract from Bazzania trilobata at concentrations of $0.5(\mathrm{~A}), 0.1(\mathrm{~B})$ and $0.05 \% \mathrm{~m} \mathrm{v}^{-1}(\mathrm{C})$.

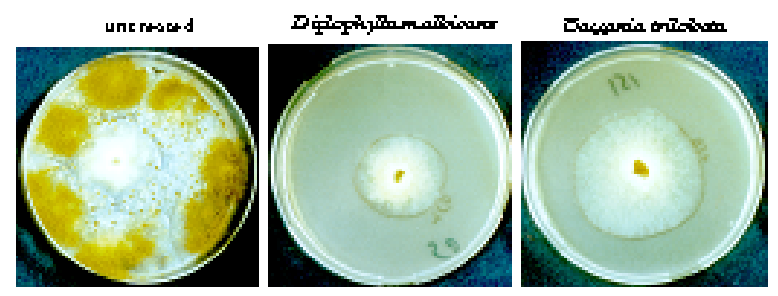

Fig. 3. Mycelium growth of Botrytis cinerea on PDA amended with $0.5 \% \mathrm{~m} \mathrm{v}^{-1}$ extracts from the liverworts Diplophyllum albicans and Bazzania trilobata.

\section{Plant protection activity against Botrytis cine- rea}

The screening of ethanolic extracts from 17 bryophytes as potential sources of active substances for protective application against infection with $B$. cinerea on green pepper demonstrated significant variations between the various treatments. The efficiency of the extracts in reducing grey mould disease reached up to $23 \%$. Only extracts from $D$. denudatum, $D$. albicans, $R$. loreus, S. quinquefarium and B. trilobata caused significant reduction of grey mould (15 to $23 \%$ ) as compared to untreated plants. Significantly higher degrees of efficiency (92\%) were recorded following application of the fungicide dichlofluanid at $50 \mathrm{ppm}$.

Active constituents from leafy liverworts exhibited significantly superior effectiveness in reduction of foliage damages of test plants. This was manifested by high level of efficacy in both tested pathosystems and their inoculum densities 
(Figs $4 \mathrm{a}$ and $\mathrm{b}$ ). On average, the protective application of the Bazzania and Diplophyllum extracts reduced the disease severity of late blight of tomatoes and powdery mildew of wheat by more than $65 \%$.
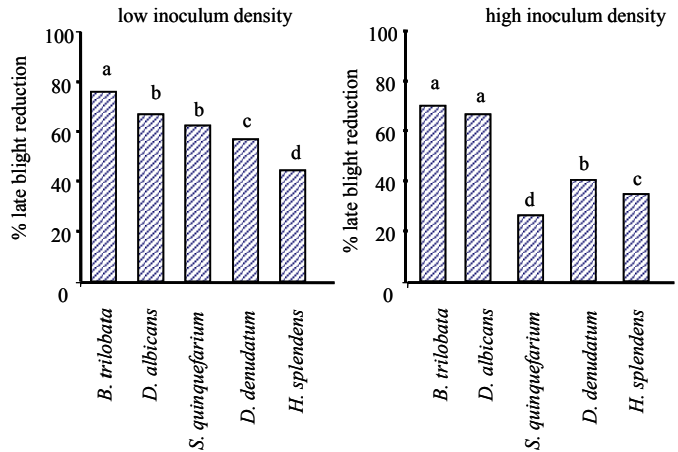

Fig.4a. Antifungal activity of the moss extracts against Phytophthora infestans on tomatoes in dependence of inoculum density. Same letters indicate no significant differences according to the Tukey-test, LSD $\alpha_{0.05}=$ $3.2 \%$, C.V. $=8.5 \%$ (for low inoculum density) and LSD $\alpha{ }_{0.05}=1.7 \%$, C.V. $=4.8 \%$ (for high inoculum density) $\mathrm{P}<0.001$.
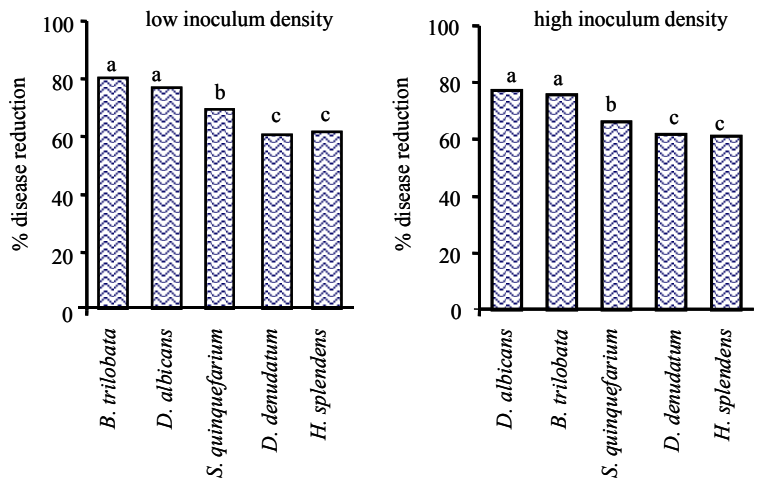

Fig.4b. Antifungal activity of the moss extracts against Blumeria graminis on wheat in dependence of inoculum density. Same letters indicate no significant differences according to the Tukey-test LSD $\alpha_{0.05}=2.5 \%$, C.V. $=7.5 \%$ (for low inoculum density) and LSD $\alpha_{0.05}=1.8 \%$, C.V. $=4.5 \%$ (for high inoculum density) $\mathrm{P}<0.001$.

Products from mosses (S. quinquefarium, D. denudatum, and H. splendens) resulted in inconsistent efficacy responses. The highest percentages of disease protective activity $(>44 \%)$ of products from these mosses were attained in experiments conducted only at low inoculum density of $P$. infestans on tomatoes (Fig. 4a). Such spectrum of disease protective activities of the mosses was slightly be better expressed against infection density of B. graminis on wheat plants (Fig. 4b).

\section{Plant protection activity in dependence of appli- cation intervals}

The efficacy of moss extract sources (MES) in relation to the application intervals $(\mathrm{T})$ for the hostpathogen-relationship models of $P$. infestans / tomatoes and B. graminis / wheat are shown in
Figs $5 \mathrm{a}$ and $5 \mathrm{~b}$. In all investigations, the scope of disease suppressive natures of moss extracts indicated two types of mode-of-action, namely direct protective and indirect activities of substances.

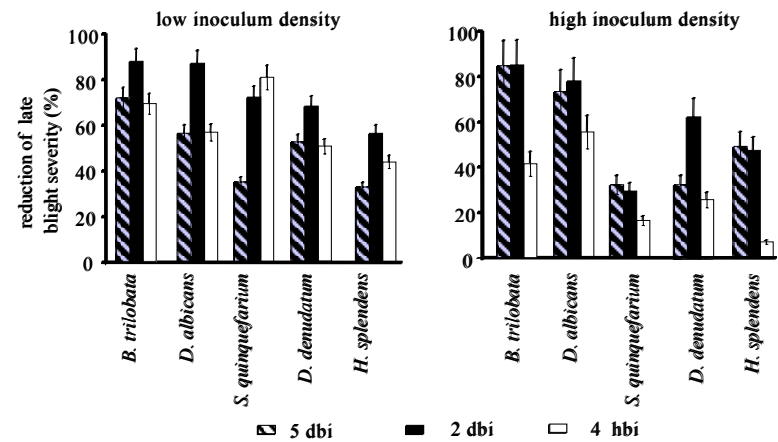

Fig. 5a. Effects of selected extracts from bryophytes (0.5\% $\mathrm{m} / \mathrm{v}$ ) in dependence of pre-inoculation application intervals against low and high inoculum densities of Phytophthora infestans on tomatoes. Interactions MES $\mathrm{X} \mathrm{T}, \mathrm{LSD} \alpha_{0.05}=4.1 \%, \mathrm{C} . \mathrm{V} .=4.1 \%$ (low inoculum density) and LSD $\alpha 0.05=2.1 \%$, C.V. $=5.8 \%$ (high inoculum density), $\mathrm{P}<=0.001$.

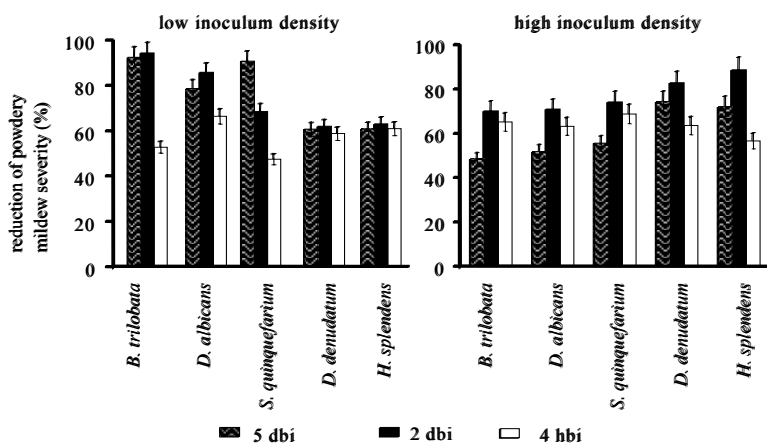

Fig. 5b. Effects of selected extracts from bryophytes $(0.5 \%$ $\mathrm{m} / \mathrm{v}$ ) in dependence of pre-inoculation application intervals against low and high inoculum densities of Blumeria graminis on wheat. Interactions MES $X$ T, LSD $\alpha{ }_{0.05}=3.1 \%$, C.V. $=9.1 \%$ (low inoculum density) and LSD $\alpha_{0.05}=2.0 \%$, C.V. $=5.0 \%$ (high inoculum density), $\mathrm{P}<=0.001$.

The direct mode-of-action of the extracts was demonstrated by the efficiency in reduction of infection rate of the pathogens when plant treatments were applied 4 hours before inoculation. Such direct protective nature of substances appeared to be moderately higher against infection severity of powdery mildew of wheat than that of late blight of tomatoes. An exception was the higher efficacy level $(>80 \%)$ of extracts from $S$. quinquefarium in restraining infection severity in the experiment using low inoculum density of late blight on tomatoes. Application of extracts from all five tested bryophytes at least two days before inoculation with the challenge pathogens on the host plants depicted significantly effective and more 
pronounced disease protective activities than the immediate application of substances 4 hours before inoculation. Again the deviation was only the higher indirect efficacy (>85\%) levels of extract from $S$. quinquefarium against the low inoculum density of powdery mildew of wheat applied 5 days prior to inoculation.

Extracts from the leafy liverworts showed a persistent and high level of efficacy, raising up to $85 \%$ against infection gradients of $P$. infestans on tomatoes and up to $95 \%$ against low inoculum density of B. graminis on wheat. The interval between applications and inoculations significantly influenced the effectivity and the indirect mode-ofactions of the extracts.

Analysis of data for the possible interrelationships between application dosages and efficacy response of tested substances produced variable results according to spray intervals of extracts. Higher amounts of substances caused statistically increased efficiency levels on late blight and powdery mildew, when the test plants were treated with the product only 4 hours before inoculation. The application of extracts from the two liverworts at 2 and 5 days before the challenge inoculation did not express any significant varied dose-dependant efficacy response. The application of lower amounts $\left(0.1 \% \mathrm{mv}^{-1}\right)$ of the liverwort extracts at 2 days before inoculation rather displayed an improved efficacy response from 30 to $60 \%$ in contrast to the application of the same dose level at 4 hours before inoculation with the pathogens. The reaction of treated tomato plants against infection of $P$. infestans was shown, fore instance (Fig. 6), by exhibiting low numbers of brown, necrotic and tiny lesions on inoculated leaves after initial penetration and tissue colonisation of the fungus to the host. These observations may indicate certain stimulatory activities of liverwort extracts to host factors in producing internal resistance against infection mechanisms of both late blight of tomatoes and powdery mildew of wheat.

\section{DISCUSSION AND CONCLUSION}

The results indicate that bryophytes contain biologically active substances against a wide range of plant pathogenic fungi. In vitro antifungal activities are described, especially in the fields of human medicine (Flowers, 1957; Ding; 1980; Asakawa and Heidelberger, 1982; Ando and Matsuo, 1984). McCleary and Walkington (1966) studied ethanol extracts of 50 different moss species against the micro-organisms Gaffkya tetragena and Staphylococcus aureus and detected effective extracts from bryophytes such as Dicranum fuscescens, Hylocomium proliferum, and
Sphagnum cuspidatum. In our experiments, extracts from B. trilobata, D. albicans, S. quinquefarium, D. denudatum and $H$. splendens inhibited the mycelial growth of $B$. cinerea and $A$. solani more efficiently than extracts from the other tested species of bryophytes. Finding of such variability between extract sources implies, that there exist chances to select the better antifungal sources for further developmental works. The attributed variations may be resolved by searching for an appropriate extraction procedures for each species.

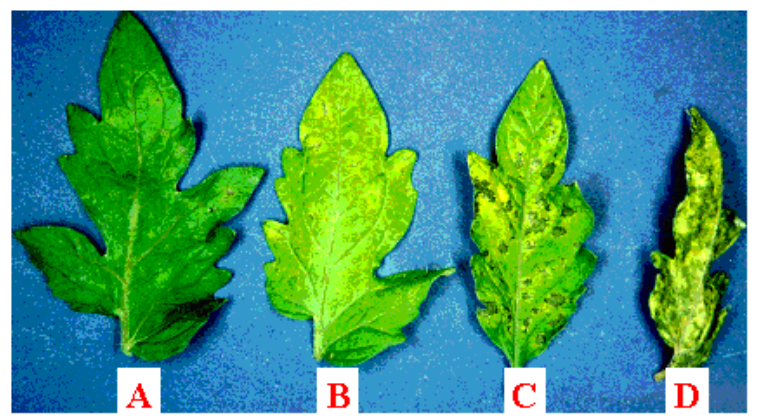

Fig. 6: Symptoms of late blight (Phytophthora infestans) after treatment with Diplophyllum albicans extracts $(\mathrm{A}=5$ days, $\mathrm{B}=2$ days, $\mathrm{C}=4$ hours before inoculation, and $\mathrm{D}=$ untreated control).

In vivo screening demonstrated the plant protection activity of ethanol extracts in some of 17 different bryophytes applied 4 hours before inoculation against grey mould of green pepper. This result was in contrast to the high in vitro antifungal activity observed against B.cinerea. However, the low in vivo efficacy level of the extracts might be evolved from very high inoculum density of the pathogen with a $25 \mathrm{ml}$ spore suspension $\left(1 \times 10^{6}\right.$ conidia $\left.\mathrm{ml}^{-1}\right)$ per leaf. Secondly, the test preparation might have not a direct, but a more indirect antifungal effect, that usually needs an adequate time gap between the application of products and inoculation of the pathogen to the host.

Results of further different in vivo experiments by using multifactorial pre-inoculation application intervals with extracts from the five bryophytes Bazzania trilobata, Diplophyllum albicans, Sphagnum quinquefarium, Dicranodontium denudatum, and Hylocomium splendens exposed two types of modeof-action, namely direct and indirect types of disease protection. Such types of mode-of-action and significant variations between antifungal activities might be attributed to the quantitative and qualitative differences in active constituents between the various moss extract sources.

Up to date it seems that there exists a lack of research information in supporting in vivo disease protective activities of moss extracts in crop protection. In contrast, different authors reported of direct protective activities of extracts from 
higher plants (Frank and Michael, 1977; Blaeser et al., 1998). In vivo antifungal activities of moss extracts reported by Mekuria et al. (1998; 1999) agreed with comparable effectiveness of extracts from higher plants.

All tested extracts showed high level of efficacy for application intervals of at least two days before inoculation with the pathogens, it means there existed indirect or systemic mode-of-action. The indirect mode-of-action of substances varied significantly between extract sources and inoculum density of the tested pathosystems. Such effects are supposed to be evolved from interactions between host factors and pre-disposed extract agents as criteria of additive and synergistic activity of chemical compounds. This can, probably, indicate an activation of host defence mechanisms to impair infection of $P$. infestans (Stierl et al., 1996).

There was an apparent reaction of susceptible host plants expressing symptoms and collapsing before further growth and tissue colonisation with the tested pathogens after initial infection into the host tissue, as compared to the initial infection and further tissue colonisation of late blight of tomatoes on untreated plants. Besides, the late blight and powdery mildew pathogens naturally proceed entirely different mechanisms of infection, establishment, invasion and cellular localisation of their host for effective disease development. Their cell walls are also composed of different types of molecular polymers. Effective control of both pathosystems using liverwort extracts and allowing optimum preinfectional application intervals denotes, that those facts greatly resemble the characteristics of induced resistance reactions described to crop plants (Steiner and Schönbeck, 1997).

In our studies, active components of the extracts from $B$. trilobata and $D$. albicans attained the opportunity to detect local and systemic protective efficiency to restrain infection severity and development of $P$. infestans on tomatoes (Mekuria Tadesse et al., 1999). The current progresses in research also indicate that active components of liverworts are localised in lysosome-like-organelles (LLOs) of B. trilobata (Mekuria Tadesse et al., 2002) which consists of hydrolytic enzymes. LLOs are known to contain more than 40 different types of enzymes like lipase, phosphatase, acid hydrolase, protease, RNAse, DNAse, esterase, cytochrome oxidase, ethanol dehydrogenase, etc. (Matile, 1969; Bainton, 1981; Larcher, 1995). Chitinase enzymes are recognised as a signal protein for resistance induction in crop plants (Orlando and Guillemond, 1994), a component of inducible defences of plants showing direct antifungal activities (Susan et al., 1988). These enzymes have different classes which vary in structure, cellular location and enzymatic activities, and, their synthesis are regulated by developmental stimuli, exogenous hormones, and pathogenic infection (Payne et al., 1990; Broglie and Broglie, 1993). Likewise, research findings indicated that the application of ethanol extracts from the medicinal plant Reynoutria sachalinensis on cucumbers increased the activation of chitinase, $\beta 1,3$-glucanase, polyphenol-oxidase, phenylalaninammoniumlyase and peroxidase to impair systemically infection severity of powdery mildew (Herger et al., 1988; Schneider et al., 1990).

The differences between species of Hepaticae and Musci in potentials and degrees of inhibition of biological activities in tested fungi imply the existence of diverse sources of crop protection substances, though extracts from $B$. trilobata and $D$. albicans shared mostly similar types of mode-ofaction. In general, the crude extracts or active components of bryophytes, such as from $B$. trilobata, deserved to be tangible sources as biotic crop protection agents and may play significant roles for future practical applications in a socially and ecologically healthy crops management system. Thus, it would be empirically advisable for advancement of the current findings and further proper exploration of the biodiversity of bryophytes, particularly in a country like Ethiopia where there exist enormous taxa at alarming rates of extinction due to deforestation and habitat degradation.

\section{ACKNOWLEDGEMENTS}

Thanks are forwarded to Prof. Dr. J.P. Frahm (Institute for Systematic Botany, University of Bonn) for his provision of bryophyte samples during experimental works. We are also indebted to the Ethiopian Agricultural Research Organization (earo), Addis Ababa and Jimma; the 'Katholischer Akademischer AusländerDienst' (kaad), Bonn; and arts programme (Agricultural Sciences and Resource Management in the Tropics and Subtropics, Faculty of Agriculture, University of Bonn) for supports to the first author during the initial phase of this project.

\section{REFERENCES}

1. Abbott, W.S. (1925). A method of computing the effectiveness of an insecticide. J. Econ. Entomol. 18:265-267.

2. Ando, H. and Matsuo, O. (1984). Applied Bryology. In: Advances in Bryology, pp.133-124 (SchultzeMotel, ed.). Vaduz.

3. Ange, S. (1996). Economic analysis of crop protection policy in Costa Rica. In: Pesticides Policy Project Publication Series, 4, Hanover, Germany.

4. Asakawa, Y. and Heidelberger, M. (1982). Chemical constituents of the Hepaticae. Progress in Chemistry of Organic Natural Products. Springer Verlag, Wien, New York, p. 42. 
5. Bainton, D. (1981). The discovery of lysosomes. Journal of Cell Biology 91:66-76.

6. Bekele Kassa and Yaynu Hiskias (1996). Tuber yield loss assessment of some potato cultivars with different levels of resistance to late blight. In: Proceedings of the 3rd Annual Conference of Crop Protection Society of Ethiopia (Eshetu Bekele, Abdurahman Abdulahi and Aynekulu Yamane, eds), CPSE, Addis Abeba, Ethiopia.

7. Blaeser, P., Steiner, U. and Dehne, H.W. (1998). Plant extracts with antifungal activity. In: Deutsche Pflanzenschutz-Tagung, 5-8. Oktober 1998, Halle/Saale, Mitt. BBA, 357:167.

8. Broglie, R. and Broglie, K. (1993). Chitinase gene expression in transgenic plants: a molecular approach to understanding plant defence responses. Philosophical Transactions of the Royal Society, Series B London, 342:265-270.

9. Dayan, F.F., Romagni, J.G., Tellez, M.R., Rimando, A.M. and Duke, S.O. (1999). Managing weeds with natural products. Pesticide Outlook 5:185188.

10. Ding, H. (1980). Medicinal Spore Bearing Plants of China. Shanghai, p. 499.

11. FAO (2001). Obsolete pesticides threaten communities in Ethiopia. News and Highlights, May 9, 2001.

12. Flowers, S. (1957). Ethnobryology of the Gosuite Indians of Utah. The Bryologist 60:11-14.

13. Frahm, J.P. and Frey, W. (1992). Moosflora. Stuttgart, p. 522.

14. Frank, E.B. and Michael, R.T. (1977). Isolation, purification, identification, synthesis and kinetics of the activity of the anti-candidial components of Allium satioum, and hypothesis for its mode of action. Mycologia 69:793-825.

15. Friedland, J. (1997). Arzneiformenlehre für Pharmazeutisch-technische Assistenten. G.-FischerVerlag, Frankfurt.

16. Girma Tesfahun, Wondimu Bayu, and Adane Tesfaye (2000). Indigenous crop pest management techniques in Welo. Pest. Mgt. J. Eth. 4(1\&2):97103.

17. Herger, G., Klingauf, F., Mangold, D., Pommer, E.-H. and Scherer, M. (1988). Die Wirkung von Auszügen aus dem Sachalin-Staudenknöterich, Rheynoutria sachalinensis (F. Schmidt) Nakai, gegen Pilzkrankheiten, insbesondere Echte Mehltau-Pilze. Nachrichtenbl. Deut. Pflanzenschutzd. 40(4):56-60.

18. Jacobson, M. and Crosby, D.G. (1971). Naturally Occurring Insecticides. Marcel Dekker, New York, p. 585.

19. Kurt, H.B. (1997). Pharmazeutische Technologie. GustavFischer-Verlag, Frankfurt (Main), Germany.

20. Larcher, W. (1995). Physiological plant ecology: ecophysiology and stress physiology of functional groups, 3rd ed. Spring Verlag, Germany, p. 299.

21. Matile, P.H. (1969). Plant lysosomes. In: Lysosomes in Biology and Pathology, Vol. 1, pp. 406-428, (Dingle, J.T. and Fell Honor B., eds) North-Holland Pub. Comp. Amsterdam.

22. McCleary, J.A. and Walkington, D.L. (1966). Mosses and antibiotics. Rev. Bryol. Lichenol. 34:309-314.
23. Mekuria Tadesse, Blaeser, P., Steiner, U. and Frahm, J.P. (1998). Effects of moss extracts against phytopathogenic fungi. In: Deutsche PflanzenschutzTagung, 5-8. Oktober 1998, Halle/Saale, Mitt. $B B A, 357: 167-168$.

24. Mekuria Tadesse, Blaeser, P., Steiner, U. and Dehne, H.-W. (1999). Bryophytes as a new source of anti-fungal substances in crop protection. In: Modern Fungicides and Anti-fungal Compounds II, pp. 483-490, (Lyr H, Russell P E, Dehne H-W and Sisler H D; eds). Intercept, U.K.

25. Mekuria Tadesse, Steiner, U. and Dehne, H.-W. (2002). Extracts from the liverwort Bazzania trilobata (L.) S.F. Gray for plant protection against fungal pathogens. In: Modern Fungicides and Antifungal Compunds III, pp. 401-408, (Dehne, H-W, Gisi U, Kuck K H, Lyr, H, and Russell, P.E, eds). AgroConcept GmbH, Germany.

26. Miehe, G. and Miehe, S. (1994). East African bryophytes, XII. Bryophytes from the Bale Mountaines, SE Ethiopia. 1. Phyto-ecological introduction. Frag. Flor. Geobot. 39(1):165-219.

27. O'Shea, B.J. (1997). The mosses of Sub-Sahara Africa. 2. endemism and biodiversity. Tropical Bryology 13:75-85.

28. Oerke, E.C., Dehne, H.-W., Schönbeck, F. and Weber, A. (1994). Crop Protection and Crop Production. Estimated Losses in Major food and cash crops. Elsevier, Amsterdam, p. 808.

29. Orlando, P. and Guillemond, B. O. (1994). Host Wall Alteration by Parasitic Fungi. APS Press, USA.

30. Payne, G., Ward, E. and Gaffney, T. (1990). Evidence for a third structural class of $\beta$-1:3-glucanase in tobacco. Plant Mol. Biol. 15:797-808.

31. Schneider, S., Herger, G., Huger, A.M., Klingauf, F. and Ullrich, W. (1990). Der Einfluß eines wäßerigen Extraktes aus dem SachalinStaudenknöterich, Rheynoutria sachalinensis auf den Echten Mehltau an Gurken und auf die Enzymaktivität der Wirtspflanze. Mitt. BBA. 266:221.

32. Steiner, U. and Schönbeck, F. (1997). Induced resistance. In: Resistance of Crop Plants Against Fung pp. 272-297, (Hartleb, H., Heitefuss, R. and Hoppe, H.-H., eds). Gustav-Fischer-Verlag, Frankfurt.

33. Stierl, R., Steiner, U. and Dehne, H.-W. (1996). Effects of induced resistance on the development of a tomato leaf pathogen. Med. Fac. Landbouww. Univ. Gent. 61(2a):201-208.

34. Susan, A.H., John, N.B., Thomas, B. and Christopher, J.L. (1988). Chitinase cDNA cloninig and mRNA induction by fungal elicitor, wounding and infection. Plant Physiol. 86:182-186. 